doi.org/ I0.51891/rease.v8ir.3776

\title{
O PAPEL DO (A) PSICÓLOGO (A) NA REINSERÇÃO SOCIAL DE PESSOAS QUE ESTIVERAM NO PROCESSO DE CUIDADO PARA O USO ABUSIVO DE ÁLCOOL E OUTRAS DROGAS
}

\author{
Sandro Manoel do Nascimento ${ }^{1}$
}

RESUMO: O trabalho apresentado versou sobre uma das mais importantes e desafiadoras áreas das políticas públicas sobre drogas no Brasil - a reinserção social de pessoas que estiveram no processo de cuidado para o uso abusivo ${ }^{2}$ de álcool e outras drogas. Teve como objetivo geral, analisar o papel do (a) psicólogo (a) neste processo. Visando alcançar este objetivo, foi realizado o seu desdobramento em alguns objetivos específicos, que abordaram a questão da relação do humano com as substâncias psicoativas, apresentou as políticas públicas sobre álcool e outras drogas no Brasil. Buscou também discutir sobre a prática profissional do (a) psicólogo (a) em um dos principais espaços de cuidado para as pessoas que sofrem em decorrência de sua relação abusiva com as drogas, que são os Centros de Atenção Psicossocial (CAPS). Uma das propostas mais inovadoras na problemática da saúde mental no Brasil, e uma das estratégias mais eficientes na substituição do antigo modelo asilar. A pesquisa realizada foi de natureza qualitativa, de revisão bibliográfica analítica, documental e interdisciplinar. Tendo como fontes de estudos plataformas digitais, como: Scielo, Pepsic e Lilacs. Visando aumentar o arcabouço teórico da pesquisa, foram analisadas obras literárias, leis e decretos que corroboraram para temática abordada. Depois de realizarmos análise do material pesquisado, ficou compreendido que a relação do humano com as drogas é uma relação de busca de prazer, interação social, religiosa, mística, dentre outras motivações. No contexto das políticas públicas sobre drogas, constatou-se que tanto no âmbito municipal, estadual e federal, elas se mostram insuficientes para atender as demandas da sociedade contemporânea. Sobre a atuação do (a) psicólogo (a) no cuidado das pessoas que se encontram no processo de reinserção social, foi analisado que por meio de suas intervenções o (a) psicólogo (a) desempenha um papel de grande relevância neste processo.

Palavras-Chaves: Drogas. Reinserção Social. Psicologia.

ABSTRACT: The work presented was about one of the most important and challenging areas of public policies on drugs in Brazil - the social reinsertion of people who were in the care process for the abuse $e^{2}$ of alcohol and other drugs. Its general objective was to analyze the role of the psychologist in this process. Aiming to achieve this objective, it was developed into some specific objectives, which addressed the issue of the human relationship with psychoactive substances, and presented public policies on alcohol and other drugs in Brazil. It also sought to discuss the professional practice of psychologists in one of the main spaces of care for people who suffer as a result of their abusive relationship with drugs, which are the Psychosocial Care Centers (CAPS). One of the most innovative proposals in the issue of mental health in Brazil, and one of the most efficient strategies to replace the old asylum model. The research carried out was of a qualitative nature, with an analytical, documental and interdisciplinary bibliographic review. Having as sources of studies digital platforms, such as: Scielo, Pepsic and Lilacs. Aiming to increase the theoretical framework of the research, literary works, laws and decrees that corroborated the theme addressed were analyzed. After performing an analysis of the researched material, it was understood that the human relationship with drugs is a relationship of seeking pleasure, social, religious, mystical interaction, among other motivations. In the context of public policies on drugs, it was found that both at the municipal, state and federal levels, they are insufficient to meet the demands of contemporary society. About the role of the psychologist in the care of people who are in the process of social reintegration, it was analyzed that through their interventions, the psychologist plays a very relevant role in this process.

Keywords: Drugs. Social reinsertion. Psychology.

\footnotetext{
${ }^{\mathrm{I}}$ Psicólogo, pós-graduado em saúde mental com ênfase em dependência química. Assistente Social. Pós-graduado em Gestão de Programas e Projetos Sociais.E-mail: sandromnascimento@gmail.com

${ }^{2}$ Este uso é causador e/ou contribui de maneira considerável para alguns danos físicos, psicológicos e sociais na dinâmica de vida do indivíduo. Tendo afetado sua capacidade de julgamento e/ou disfunção de comportamento (BRASIL, 2014).
} 


\section{INTRODUÇÃO}

O uso de drogas é uma prática milenar na história da humanidade, que ainda permanece presente em distintas sociedades. Esta relação está associada às tradições socioculturais, rituais místicos e religiosos, diversão, relaxamento, prazer, e até mesmo como facilitador de interação social. Ou seja, a relação do humano com as substâncias psicoativas perpassa o contexto de apenas uma relação danosa.

Podemos tomar como exemplo a relação com o Ópio, que é utilizado há mais de cinco mil anos, e que já foi considerado como uma dádiva dos deuses, e utilizado para o alívio das dores (BRASIL, 2014). Destacamos também o uso da Cannabissativa, popularmente conhecida como Maconha, que tem uma relação milenar com a humanidade, pois foram encontrados vestígios da mesma em uma porcelana de origem chinesa, que tem aproximadamente quatro mil anos. Suas fibras já foram utilizadas para a confecção de cordas, tecidos, para tratamento oftalmológico, febre, insônia e outras enfermidades. Ainda sobre a relação com a Maconha, ela tem sido utilizada em vários tratamentos câncer, dor crônica, epilepsia dentre outras doenças, possibilitando assim para esses pacientes uma melhor qualidade de vida (FIOCRUZ, 2020).

$\mathrm{Na}$ sociedade contemporânea o uso das drogas tem sido considerado como o responsável por doenças, aumento da violência, dentre outros problemas, mas foi os EUA o precursor desta perspectiva, que levou ao início do movimento proibicionista. Que tinha e tem intrinsecamente em sua proposta o controle social de alguns grupos que já vinham e vêm sendo estigmatizados - Negros, pobres, latinos, dentre outros imigrantes. Considerados por eles, como os grandes consumidores de drogas. Essas campanhas tinham e têm uma concepção racista e moralista (BRASIL, 2014).

Acreditava-se (e ainda acreditam) que por meio de leis proibicionistas, iriam dar um fim ao consumo das drogas, mas como findar algo que está na essência da humanidade, algo que a constitui, que é a sua relação com as drogas.

Esses movimentos proibicionistas nos EUA influenciaram a aprovação de leis que buscavam controlar e coibir a relação das pessoas com as drogas. Em I9I4 foi instituída a lei de controle do ópio e cocaína, em I9r9 a lei que trouxe a proibição do uso do álcool, também conhecida como a lei seca. Esta que esteve em vigor entre os anos de 1920 a 1932. Neste período houve um grande aumento da violência em decorrência do tráfico de bebidas 
alcoólicas. A maconha também entrou neste rol das substâncias proibidas no ano de 1930 . (BRASIL, 2014)

Os EUA influenciaram este movimento a nível internacional, no qual quase todos os países do mundo aderiram a esta proposta proibicionista. Assinando alguns acordos, em 1961 a Convenção de Viena e em 197ı o Convênio sobre Substâncias Psicotrópicas. A intenção inicial que eles defendiam era dar um fim ao consumo de drogas. O Brasil é um dos países signatários destes acordos. (BRASIL, 2014).

Culpabilizar as drogas e as pessoas que têm uma relação com as mesmas, por todos os problemas sociais que vêm assolando a sociedade, é no mínimo um ato de covardia e fuga das responsabilidades dos governantes e de sua ineficiência na garantia de direitos básicos para a população. Pois o que se constata é uma má distribuição de renda, educação abandonada, saúde e segurança pública sucateadas. Então atribuir a uma parcela da sociedade, que é constituída de pessoas negras, pobres e periféricas, é uma ação premeditada de governos corruptos, covardes, racistas e preconceituosos, que desejam o controle dessas massas e o aumento dos estigmas das mesmas (BRASIL, 2014).

A relação Brasil/drogas/lei já existe desde o período colonial, no qual já em 1603 as pessoas que tinham envolvimento com as drogas, poderiam ter seus bens e posses tomados.

E o país permaneceu neste mesmo pensamento, quando em 1912 tornou-se participante da Conferência Internacional do Ópio. Continuando nesta visão proibicionista na perspectiva internacional, como já foi citada anteriormente na sua adesão a influência dos EUA. No ano de 1940 por meio do Código Penal, a alternativa de não criminalização do consumo, mas em contrapartida as pessoas eram internadas obrigatoriamente e submetidas a tratamentos desumanos. Em 1964 no período do início da ditadura militar, os traficantes eram considerados com inimigos do Estado. Em 1973 a adesão ao acordo Sul-Americano sobre Estupefacientes e Psicotrópicos, que serviu de base para a lei 6.368/1976, lei que diferenciou a figura do traficante e usuário. A Constituição em 1988 definiu o tráfico como crime inafiançável e a lei 8.072/90 como crime hediondo. Já a lei II.343/2006 extinguiu a pena de prisão para o usuário e/ou dependente e trouxe também a distinção de que seria o traficante profissional e a pessoa que trafica de forma eventual para a manutenção de seu uso (BRASIL, 2020).

Para algumas pessoas o uso de substâncias psicoativas poderá ocasionar uma relação danosa, que por sua vez poderá levar ao rompimento dos vínculos familiares, sociais e 
afetivos. Ou seja, a dinâmica social dessas pessoas as leva a uma condição de exclusão social. Na qual grande parte da sociedade as considera, como alguém que não tem mais direito a ter direitos. E se encontra a margem da própria sociedade, essa posição "marginal" não é uma escolha do indivíduo, pois ele foi impelido pela própria sociedade a estar nesta condição de vulnerabilidade e risco social. Ao estar nesta condição em decorrência da sua relação problemática com o uso abusivo de álcool e outras drogas, o indivíduo busca um processo de tratamento em espaços de cuidado ou é encaminhado por um familiar/substituto para estes espaços. Neste momento já se inicia o seu processo de reinserção social.

Discutir o tema de reinserção social nos transporta a uma das lutas mais antigas que vem sendo travada por muitos - a luta antimanicomial. E nesta perspectiva queremos destacar uma das leis que foi um marco histórico, a Lei no 10.216 , de 6 de abril de 2001. Esta traz a proteção e a garantia de direitos das pessoas que sofriam de algum tipo de transtorno mental, e não mais o modelo asilar, que "tratavam" as pessoas de maneira desumanas. No artigo $4^{\underline{o}}$, parágrafo $\mathrm{I}^{\mathrm{o}}$ vem destacando que a finalidade primordial do tratamento é a reinserção social destas pessoas (BRASIL, 200I). Um dos espaços de cuidado para estas pessoas são os CAPS - Centro de Atenção Psicossocial, espaço este no qual foi analisada atuação do (a) psicólogo (a) na temática da reinserção social.

O Ministério da Saúde (MS) no início do ano 2000 normatizou as diretrizes para a criação e funcionamento dos Centros de Atenção Psicossocial - Álcool e Drogas (CAPSAD) que teve a sua estrutura redefinida em 2012 por uma nova portaria (BRASIL, 2012). Posteriormente foram criados os CAPS - AD 24 horas, que além dos serviços já disponibilizados e das responsabilidades de gestão realizadas pelo CAPS - AD regular, funcionam diariamente de modo ininterrupto, inclusive nos feriados e finais de semana (BRASIL, 2012).

No ano de 2019 foi promulgada pelo então presidente Jair Messias Bolsonaro, a nova lei sobre drogas, a Lei Federal n. ${ }^{\circ}$ 13.840, de 5 de junho de 2019. Esta lei alterou a lei anterior que tinha uma proposta inovadora na questão das políticas públicas sobre droga - Lei n.. II.343 de 23 de agosto de 2006, decretada pelo então presidente Luiz Inácio Lula da Silva, mas no quesito da reinserção social, não houve alterações.

Tecendo uma crítica sobre as políticas públicas sobre drogas no Brasil, ambas as leis não trazem em seu bojo uma quantificação sobre o que seria tráfico ou uso pessoal. O que 
fará esta distinção será o contexto em que a droga foi apreendida, dando margem para os preconceitos e estigmas sociais. Nesta lei consta que o juiz levará em conta o local e as condições que se deu a apreensão das drogas, ou seja, se um jovem negro for detido em uma comunidade pobre, e se ele já cometeu algum delito, isso será um agravante que ocasionará o seu encarceramento. (BRASIL, 2006).

Outrossim, fazem parte da estratégia política e ideológica voltada ao encarceramento em massa e criminalização da pobreza de grupos marginalizados socialmente. O Levantamento Nacional de Informações Penitenciárias de 2017 corrobora com esta análise, pois de acordo com o mesmo, temos hoje encarceradas 752.277 pessoas, $95,33 \%$ homens, desses $29,95 \%$ são jovens, que possuem idade entre 18 a 29 anos, 63,5\% de negros, que seria a junção dos que se declaram pardo de 46,2\% e pretos 17,3\%. (DEPEN, 2019).

Voltando à questão da reinserção social, e o seu arcabouço legal. $\mathrm{O}$ artigo $22^{\circ}$ do Capítulo II da Lei Ir.343/2006 (que ainda se encontram vigentes) trata também das atividades de reinserção social de pessoas que fazem o uso abusivo de substâncias psicoativas. O qual destaca nos seus incisos I e II seus princípios e diretrizes, no que se refere às pessoas que fazem o uso de drogas e aos seus familiares. E a implantação de estratégias que visem à reinserção social destes.

Nos âmbitos estaduais e municipais, também temos algumas leis que tratam da reinserção social. A Lei Estadual no 14.56 I, de 26 de dezembro de 20II, promulgada pelo então governador em exercício João Soares Lyra Neto, trata a questão da reinserção social, sempre associado à acolhida, proteção e tratamento. (PERNAMBUCO, 20II). Como também o Decreto municipal da cidade do Recife, $\mathrm{n}^{\circ}$ 27.54I, de 25 de novembro de 2013 . Mas no âmbito municipal, a temática da reinserção social está atrelada a prevenção e cuidado. (RECIFE, 2013).

Ao iniciar a discussão a respeito do lugar do (a) psicólogo (a) neste campo de atuação, foi apresentada a Rede de Atenção Psicossocial (RAPS), a mesma foi instituída pela Lei no 3.088 , de 23 de dezembro de 20II, que estabeleceu o cuidado as pessoas que sofrem em decorrência do uso de álcool e outras drogas. Em seu artigo $4^{-}$, inciso IV, tem como um de seus objetivos a reinserção social (BRASIL, 20II). Sendo o CAPS um dos equipamentos da RAPS foi à estratégia de cuidado escolhida para ser analisada por esta pesquisa. Na qual a atuação do (a) psicólogo (a) vem numa perspectiva de uma intervenção libertária (CFP, 2013). 


\section{MÉTODO}

Este trabalho foi fruto de uma pesquisa bibliográfica de natureza qualitativa, analítica e descritiva, que segundo Prodanov (2013) a mesma oferece a possibilidade de análise mais abrangente do objeto de estudo. Ainda de acordo com Prodanov (op.cit), pesquisas de natureza qualitativa proporcionam uma melhor interpretação e significado dos fenômenos abordados. Considerando a relevância do fenômeno investigado, se optou para uma pesquisa qualitativa. Tendo em vista que a dinâmica deste tema não pode ser traduzida apenas em números (SILVA, 2005). Corroborando com o que já foi exposto sobre a importância e justificativa da escolha da natureza da pesquisa, Minayo (2002) diz que este modelo de pesquisa, busca o aprofundamento sobre a temática estudada. Em se tratando do cunho descritivo, recorremos a este, pois o mesmo enseja a descrição dos fenômenos e os seus significados, consolidando assim o objetivo deste trabalho (ZANELLA, 2013).

Visando alcançar os objetivos deste trabalho, foram analisados artigos científicos de plataformas acadêmicas como a SciElo, Pepsic e Lilacs, artigos estes, que se enquadravam com o assunto abordado. Os descritores utilizados na realização deste levantamento foram: Drogas; Reinserção Social; Psicologia. Em relação aos critérios de inclusão e exclusão, foram considerados os materiais publicados nos últimos 5 anos em português, que corroboravam e tinham relevância para o aprofundamento da temática discutida. Após a aplicação dos critérios de inclusão e exclusão, houve a necessidade de acréscimos no arcabouço teórico da pesquisa. Então se buscou em outras fontes, como livros, leis, sites governamentais, site do Conselho Federal de Psicologia.

Visando a manutenção dos aspectos éticos na pesquisa, todas as partes citadas de forma direta, quanto indireta foram devidamente referenciadas. Em relação os possíveis riscos trazidos pela pesquisa, não houveram, tendo em vista que a natureza desta foi de cunho bibliográfico. Salientamos que por meio da pesquisa a academia e sociedade em geral se beneficiaram, pois ela proporcionou o aprofundamento da temática estudada.

\section{RESULTADOS}

Após a aplicação dos critérios de inclusão e exclusão - artigos publicados nos últimos 5 anos em português e que tinha relevância com a temática trabalhada, foram encontrados apenas 3 artigos que estavam em consonância com a temática da pesquisa. $\mathrm{Na}$ aplicação dos descritores na plataforma SciElo, foram encontrados 2 artigos, mesmo com a alteração 
dos descritores, eles se repetiram. Na plataforma Pepsic não foram encontrados artigos congruentes com o tema e na plataforma Lilacs foram encontrados apenas um artigo harmônico com o assunto trabalhado. E o artigo Reabilitação Psicossocial e Reinserção Social de Usuários de Drogas: Revisão da Literatura, se repete nas plataformas SciElo e Lilacs. Esta escassez de material produzido sobre o assunto nas plataformas acadêmicas exigiu um movimento de busca em outras fontes de pesquisa - Literaturas, sites governamentais, leis, políticas públicas, materiais produzidos pelo Conselho Federal de Psicologia dentre outras.

Tabela I - Plataformas Pesquisadas

\begin{tabular}{|c|c|c|c|}
\hline \multirow{2}{*}{ DESCRITORES } & \multicolumn{3}{|c|}{ PLATAFORMAS PESQUISADAS } \\
\hline & SCIELO & PEPSIC & LILACS \\
\hline $\begin{array}{l}\text { Drogas; Reinserção Social; } \\
\text { Psicologia. }\end{array}$ & 2 & $\mathrm{o}$ & I \\
\hline Reinserção Social; Psicologia. & I & o & I \\
\hline Reinserção Social; Drogas. & 2 & o & I \\
\hline
\end{tabular}

Fonte: Elaborada pelo autor, 2020.

\section{DISCUSSÃO}

De acordo com Duarte (2004), para se entender o processo de reinserção social, devemos compreende o processo de exclusão social, ou seja, ser privado dos direitos básicos - moradia, trabalho, família, saúde, dentre outros.

Brasil (2014), aborda sobre o processo da dinâmica de reinserção e exclusão social:

Para entendermos o processo de reinserção [...] social, é necessário que nos reportemos ao conceito de exclusão, [...] que é o ato pelo qual alguém é privado ou excluído de determinadas funções. A exclusão social implica, pois, numa dinâmica de privação por falta de acesso aos sistemas básicos, como família, trabalho formal ou informal, saúde, entre outros. (BRASIL, 20I4, p. 62).

Ainda de acordo com Brasil (2014), a reinserção social é um processo de reconstrução das possíveis perdas causadas em decorrência do envolvimento das pessoas com o uso abusivo e/ou dependência de álcool e outras drogas.

O Conselho Nacional de Municípios (2017), ressalta que o profissional deve trazer o usuário a reflexão e compreensão do seu processo e o seu contexto de reinserção social: 
É necessário que o profissional se faça compreender pelo usuário, no sentido de que ele entenda a reinserção como um processo longo e gradativo, onde ele irá primeiro superar seus próprios preconceitos e estigmas.[...] viver sob tal condição, que é a dependência química, a reinserção social já se coloca, desde o contexto do tratamento [...]. (CNM, 2017).

Ainda se tratando da responsabilidade do usuário no seu processo de reinserção, Freitas (2005), apresenta o papel do mesmo nesta dinâmica.

A Reinserção Social exige um trabalho do indivíduo sobre si próprio, uma mobilização pessoal. O sujeito é ator da sua existência e responsável pela sua inserção. É muito importante compreender o sentido de que os sujeitos atribuem aos seus comportamentos nos diferentes domínios da sua vida. Assim, reinserção é a construção da unidade do sujeito, a procura intersignificativa entre as várias dimensões ou domínios da vida (FREITAS, 2005).

O Conselho Federal de Psicologia (CFP) traz o referencial teórico sobre a atuação do (a) psicólogo (a) no CAPS, elaborado no ano de 2013, mas este documento não aborda a atuação deste (a) profissional no CAPS-AD. O mesmo conselho reconhece a necessidade da elaboração de um documento que contemple as especificidades desta modalidade de Centro de Atenção Psicossocial - Álcool e Drogas. Tendo em vista os desafios e demandas trazidos neste espaço de trabalho do (a) psicólogo (a) (CFP, 2013).

Em relação da atuação do (a) psicólogo (a) destacamos um dos equipamentos que compõe a RAPS são os CAPS, que já foi abordado anteriormente. A modalidade de CAPS que salientamos foi o Centro de Atenção Psicossocial - Álcool e Drogas (CAPS-AD). Neste serviço através de sua atuação o (a) Psicólogo (a) busca viabilizar a autonomia do sujeito, suas potencialidades, defesa de seus direitos, como ressalta o próprio Conselho Federal de Psicologia. (CFP, 2019).

Ainda se tratando da atuação do (a) psicólogo (a) no CAPS-AD, o CFP (2019), em uma de suas obras de orientação profissional, elenca quatro eixos de que norteiam a exercício do (a) profissional de psicologia nas políticas públicas sobre álcool e outras drogas. $\mathrm{O}$ primeiro eixo versa sobre o contexto ético-político da profissão. $O$ segundo seria a atuação na rede psicossocial e na política de atenção integrada, trazendo a discussão sobre a clínica ampliada, ou seja, a atuação "além-muros". O terceiro eixo refere-se aos desafios enfrentados pelo (a) psicólogo (a) em sua prática de cunho emancipador, onde reitera o compromisso da profissão com a garantia e efetivação de direitos. O quarto eixo fala da atuação focada na pessoa que sofre em decorrência do uso abusivo de álcool e outras drogas. No qual esta pessoa tem um papel primordial na elaboração das intervenções que serão realizadas no seu processo de cuidado. 
Brasil (2014) evidencia o acolhimento como a primeira intervenção na atuação do profissional no CAPS-AD junto as pessoas que sofrem em decorrência de suas relações danosas com as substâncias psicoativas. Pontuando que acolhimento seria o momento de receber estas pessoas no espaço de cuidado, requerendo assim por parte do (a) profissional abertura para ouvir as queixas e demandas trazidas por este (a) usuário (a).

Brasil (2004) ressalta mais uma estratégia utilizada pelo (a) Psicólogo (a) no CAPS $\mathrm{AD}$ - o projeto terapêutico singular (PTS). Este instrumento que é construído de forma conjunta entre a pessoa que buscou cuidado e a equipe técnica. Cada pessoa tem o seu projeto individual, ou seja, não se deve pensar que a mesma intervenção utilizada para um (a) usuário (a), terá o mesmo efeito em outro (a). O projeto não é estático, mas sim flexível todas às vezes quanto necessário.

De acordo com o CFP (2019), outro tipo de estratégia utilizada pelo (a) psicólogo (a) na sua atuação nos CAPS-AD são as assembleias semanais de usuários (as). São espaços de escuta, que possibilitam a estas pessoas um momento de diálogo com os seus pares e com a equipe técnica. Neste espaço são debatidas as possíveis queixas e necessidades dos (as) usuários (as).

O CFP (2019) trata de outros dois modelos de intervenções trabalhadas no CAPS-AD, que são os atendimentos individuais e em grupos. Nos atendimentos individuais as pessoas que estão neste processo de cuidado têm a possibilidade de ter um ambiente de sigilo, no qual poderá trabalhar as suas demandas que ele (a) não teria oportunidade de abordá-las nos atendimentos grupais, devido às mesmas serem de âmbito privado. Já nos atendimentos grupais, a dinâmica é diferente, pois estes facilitam a troca entre os pares. Nos quais há uma possibilidade de troca de experiências vivenciadas nas suas relações com as drogas. Esses momentos além de possibilitarem a interação grupal, fortalecimentos entre os pares, também é um momento rico para o autofortalecimento das pessoas que partilham suas vivências e histórias, pois falar sobre o que lhe causa sofrimento ajudará no processo de ressignificação desta pessoa.

\section{CONSIDERAÇÕES FINAIS}

A reinserção social das pessoas que estiveram no processo de cuidado para o uso abusivo de álcool e outras drogas, tem se tornado um grande desafio, tanto para as políticas públicas, como também para suas famílias, para sociedade e principalmente para o (a) 
próprio (a) usuário (a). Este (a) que enfrenta os preconceitos e estigmas em decorrência de sua relação com as substâncias psicoativas.

Este trabalho teve como objetivo geral, discutir a relevância da atuação do (a) psicólogo (a) neste processo de reinserção. Buscando alcançar este objetivo, realizamos a análise da relação do humano com as drogas e as políticas públicas sobre drogas no país.

$\mathrm{Na}$ análise da relação do humano com as drogas, percebemos que esta nem sempre teve a conotação de uma relação danosa e abusiva, mas muito distante disso. A humanidade tem um vínculo milenar com as substâncias psicoativas. Utilizando-se delas para buscar prazer, interação social, místico, religioso, dentre outras motivações.

Em relação às políticas públicas sobre drogas, foi constatado que as mesmas ainda são insuficientes para atender as demandas da sociedade contemporânea em decorrência das diversas transformações e contextos sociais que a mesma vem passando ao longo do tempo. Políticas que não atendem as especificidades de grupos desta sociedade.

Sobre a atuação do (a) psicólogo (a) na reinserção social das pessoas que estiveram no processo de cuidado para o uso abusivo de álcool e outras drogas, ficou compreendido que este (a) profissional desempenha um papel crucial neste processo por meio de suas intervenções.

A respeito da metodologia utilizada para se alcançar os objetivos propostos, ela foi bastante efetiva, ainda que os materiais disponíveis para pesquisa nas plataformas acadêmicas da temática abordada se mostraram escassos. O que nos levou a buscar outras fontes de estudo que possibilitou dar robustez no arcabouço teórico da pesquisa.

Ainda se tratando da análise da atuação do (a) psicólogo (a) na reinserção de pessoas que estiveram no processo de cuidado para o uso abusivo de álcool e outras drogas, neste trabalho em decorrência de tempo escasso para a pesquisa foi possível estudar a atuação em um serviço, que foi o Centro de Atenção Psicossocial Álcool e Drogas (CAPS-AD). Havendo assim a necessidade de aumentar abrangência do estudo em futuras pesquisas, as mesmas devem buscar analisar esta atuação em outros espaços de cuidado.

Este trabalho possibilitou a ampliação da discussão do papel do (a) profissional de psicologia na reinserção social e suas estratégias nesta problemática. Sendo assim o material produzido por meio desta pesquisa é de suma importância para a comunidade científica e para a sociedade como um todo, tendo em vista a escassez de estudos sobre a temática abordada como já foi relatado anteriormente. 


\section{REFERÊNCIAS}

BRASIL - Lei n. ${ }^{\circ}$ Ir.343, de 23 de agosto de 2006. Institui o Sistema Nacional de Políticas Públicas sobre Drogas - Sisnad; prescreve medidas para a prevenção de uso indevido, atenção e reinserção social de usuários e dependentes de drogas; estabelece normas para repressão à produção não autorizada e ao tráfico de drogas; define crimes e dá outras providências. Disponível em: <http://www.planalto.gov.br/ccivil_03/_ato20042006/2006/lei/lin343.htm> Acesso em: 24 de março de 2020.

- Em Discussão: História do combate às drogas no Brasil. Disponível em:<https://www.senado.gov.br/noticias/Jornal/emdiscussao/dependencia- /iniciativasdo-governo-no- -drogas/historia-do-combate-as-drogas-no-brasil.aspx $>$ Acesso em: o5 de outubro de 2020 .

- Lei n.o 10.216 , de 6 de abril de 200I. Dispõe sobre a proteção e os direitos das pessoas portadoras de transtorno mentais e redireciona o modelo assistencial em saúde mental. Disponível em: 〈http://www.planalto.gov.br/LEIS/LEIS_2001/Lio216.htm〉 Acesso em: 22 de março de 2020.

- Lei n.o 13.840 , de 5 de junho de 2019. Altera as Leis $\mathrm{n}^{\mathrm{os}}{ }_{11.343}$, de 23 de agosto de 2006, 7.560, de 19 de dezembro de 1986, 9.250, de 26 de dezembro de 1995, 9.532, de io de dezembro de 1997, 8.981, de 20 de janeiro de 1995, 8.315, de 23 de dezembro de 1991, 8.706, de I4 de setembro de 1993, 8.069, de 13 de julho de 1990, 9.394, de 20 de dezembro de 1996, e 9.503, de 23 de setembro de 1997, os Decretos-Lei n ${ }^{\text {os }} 4.048$, de 22 de janeiro de 1942, 8.621, de Io de janeiro de 1946, e 5.452, de I - de maio de 1943, para dispor sobre o Sistema Nacional de Políticas Públicas sobre Drogas e as condições de atenção aos usuários ou dependentes de drogas e para tratar do financiamento das políticas sobre drogas. Disponível em: 〈http://www.planalto.gov.br/ccivil_03/_ato2019-2022/2019/lei/L13840.htm>Acesso em: 24 de março de 2020 .

- Ministério da Saúde. Secretaria de Atenção à Saúde. Departamento de Ações Programáticas Estratégicas. Saúde mental no SUS: os centros de atenção psicossocial / Ministério da Saúde, Secretaria de Atenção à Saúde, Departamento de Ações Programáticas Estratégicas. - Brasília: Ministério da Saúde, 2004.

- Portaria n.으. I.028, de Io de julho de 2005. Determina que as ações que visam à redução de danos sociais e à saúde, decorrentes do uso de produtos, substâncias ou drogas que causem dependência, sejam por esta Portaria. Disponível em:<https://bvsms.saude.gov.br/bvs/saudelegis/rtio28_oI_07_2005.html> Acesso em: 20 de março de 2020 .

- Portaria n.․ 12I, de 25 de janeiro de 2012. Institui a Unidade de Acolhimento para pessoas com necessidades decorrentes do uso de Crack, Álcool e Outras Drogas (Unidade de Acolhimento), no componente de atenção residencial de caráter transitório da Rede de Atenção Psicossocial. Disponível em: 〈https://bvsms.saude.gov.br/bvs/saudelegis/ prtoI2I_25_OI_2012.html> Acesso em: I9 de março de 2020 . 
- Portaria n.o 130, de 26 de janeiro de 2012. Redefine o Centro de Atenção Psicossocial de Álcool e outras Drogas 24 horas (CAPS AD III) e os respectivos incentivos financeiros. Disponível em: 〈https://bvsms.saude.gov.br/bvs /prto130_26_ol_2012.html> Acesso em: I5 de março de 2020.

- Portaria n.o 3.088, de 23 de dezembro de 20II. Institui a Rede de Atenção Psicossocial para pessoas com sofrimento ou transtorno mental e com necessidades decorrentes do uso de crack, álcool e outras drogas, no âmbito do Sistema Único de Saúde (SUS). Disponível em: 〈https://bvsms.saude.gov.br/bvs/prt3088_23_I2_201I_rep.html〉 Acesso em: 22 de março de 2020.

- Secretaria Nacional de Políticas sobre Drogas. Prevenção dos problemas relacionados ao uso de droga: Capacitação para conselheiros e lideranças comunitárias / Ministério da Justiça, Secretaria Nacional de Políticas sobre Drogas. 6. Ed. Brasília, DF: SENAD-MJ/NUTE-UFSC, 2014.

Confederação Nacional de Municípios - CNM. Reinserção social: o direito de recomeçar Brasília: CNM, 2017.

Conselho Federal de Psicologia (BRASIL). Referências técnicas para atuação de psicólogas (os) em políticas públicas de álcool e outras drogas [recurso eletrônico] / Conselho Federal de Psicologia. 2. Ed. Brasília: CFP, 2019.

- Referências técnicas para atuação de psicólogas (os) no CAPS - Centro de Atenção Psicossocial / Conselho Federal de Psicologia. - Brasília: CFP, 2013.

Cuidado integral ao usuário de drogas: um campo em construção/Denis da Silva Moreira (Organizador). - Alfenas - MG: Editora Universidade Federal de Alfenas, 2017.

DUARTE, P. C. A. V. Reinserção social: atualização de conhecimento sobre redução da demanda de drogas. Florianópolis: SENAD, 2004.

FUNDAÇÃO OSVALDO CRUZ: Uso medicinal da Cannabis sativa é o tema do Sala de Convidados. Disponível em: <https://portal.fiocruz.br/noticia/uso-medicinal-dacannabis-sativa-e-o-tema-do-sala- > Acesso em: or de outubro de 2020.

FREITAS, I. Comentários sobre os documentos relativos à Reinserção Social de toxicodependentes e Indicadores de Reinserção Social, 2005.

Legislação e Políticas Públicas sobre Drogas / Brasília, Presidência da República, Secretaria Nacional de Políticas sobre Drogas, 2010.

Levantamento Nacional de Informações Penitenciárias, atualização junho de 2017 / organização, Marcos Vinicíus Moura. Brasília: Ministério da Justiça e Segurança Pública, Departamento Penitenciário Nacional, 2019.

MYNAYO (Org.). Pesquisa social: teoria, método e criatividade. Petrópolis: Vozes, 2002. 
PRODANOV, Cleber Cristiano. Metodologia do trabalho científico [recurso eletrônico]: métodos e técnicas da pesquisa e do trabalho acadêmico / Cleber Cristiano Prodanov, Ernani Casar de Freitas. - 2. Ed. - Novo Hamburgo: Feevale, 2013.

PERNAMBUCO - Lei n. ${ }^{\circ}$ I4.56I, de 26 de dezembro de 20II. Institui, no âmbito do Poder Executivo, a Política Estadual sobre Drogas, e dá outras providências. Disponível em: $\langle$ http://legis.alepe.pe.gov.br/texto.aspx?id=4929\&tipo=TEXTOORIGINAL $>$ Acesso em: Io de março de 2020.

RECIFE - Decreto n. - 27.54I, de 25 de novembro de 2013. Institui o Plano Municipal de Atenção Integrada ao Crack e outras drogas no Recife. Disponível em: <https://leismunicipais.com.br/ recife/decreto/2013/2754/2754I/decreto-n-27541-2013institui-o-plano-municipal-de-atencao-integrada-ao-crack-e-outras-drogas-no-recife> Acesso em: 04 de março de 2020.

SANCHES, Laís Ramos e VECCHIA, Marcelo Dalla. Reabilitação Psicossocial e Reinserção Social de Usuários de Drogas: Revisão de Literatura. Disponível em 〈https://www.scielo.br/pdf/psoc/v30/r8o7-0310-psoc-30-e178335.pdf $\rangle$. Acesso em: is de setembro de 2020 .

SILVA, Edna Lúcia da. Metodologia da pesquisa e elaboração de dissertação/Edna Lúcia da Silva, EsteraMuszkat Menezes. - 4. ed. rev. atual. - Florianópolis: UFSC, 2005.

SILVEIRA, Maria da Penha Rosa, et al. Autonomia e Reinserção Social: Percepção de Familiares e Profissionais que Trabalham com Redução de Danos. Disponível em: 230 $\langle$ https://pesquisa.bvsalud.org/portal/resource/pt/biblio-967652〉. Acesso em i4 de setembro de 2020 .

TREVISAN, Erika Renata e Castro Sybelle de Souza. Centro de Atenção Psicossocial álcool e drogas: perfil dos usuários. Disponível em $\langle$ https://www.scielo.br/pdf/sdeb/v43ni2I/or.pdf〉. Acesso em: i5 de setembro de 2020.

ZANELLA, Liane Carly Hermes. Metodologia de pesquisa / Liane Carly Hermes Zanella. - 2. ed.reimp. - Florianópolis: Departamento de Ciências da Administração / UFSC, 2013. 